УДК 911.2:551.8(470.56)

ОСОБЕННОСТИ РАСПРОСТРАНЕНИЯ, МОРФОЛОГИЧЕСКОЕ

СТРОЕНИЕ И МЕХАНИЗМЫ ФОРМИРОВАНИЯ ЧЕТКОВИДНЫХ РУСЕЛ МАЛЫХ РЕК СТЕПНОЙ ЗОНЫ ОРЕНБУРГСКОЙ ОБЛАСТИ

\author{
Рябуха А.Г., Поляков Д.Г.
}

Институт степи УрО РАН - обособленное структурное подразделение ФГБУН Оренбургского федерального исследовательского ичентра УрО РАН, Оренбург, e-mail: annaryabukha@yandex.ru

Локальные участки русел малых рек часто имеют четковидное строение, состоящее из ритмично чередующихся по длине глубоких озеровидных расширений и соединяющих их узких проток. Четковидные русла встречаются во всех природных зонах, однако наиболее типичны для зоны распространения многолетней мерзлоты. Анализ космических снимков и полевые исследования показали их широкое распространение на территории степной зоны. В работе рассматриваются особенности распространения, морфологическое строение и механизмы формирования четковидных русловых форм малых рек степной зоны Оренбургской области. В результате проведенной работы составлена карта распространения четковидных русловых форм на территории области. Выявлено, что они распространены в долинах малых рек в бассейнах р. Урал (Кинделя, Кинделька, Иртек, Заживная, Большая Песчанка, Малая Песчанка, Большой Кумак, Малая Хобда, Карабутак, Орь, Губерля), р. Самары (Малый Кинель, Бузулук, Енкла, Именинник, Съезжая, Кувай, Лебяжка, Сорока, Сорочка), р. Сакмары (Неть, Салмыш, Янгиз, Ялонга, Чебенька, Бурунча) и многих других. Выявлено, что вне зависимости от районов их распространения на территории области реки с четковидным руслом объединяет ряд общих закономерностей. Приуроченность к участкам выполаживания продольного профиля речной долины. Обычно это водотоки 1-3 порядка с очень небольшими (менее $0,2 \%$ ) уклонами и малой мощностью водного потока. Протекают они по территориям, сложенным рыхлыми породами (лессами, суглинками, супесями). Имеют узкие долины с врезанными или адаптированными прямолинейными руслами, которые часто образуют коленообразные изгибы. Выдвинута гипотеза, что четковидные русла малых рек вне зоны существования многолетней мерзлоты являются реликтовыми формами, наследием плейстоценовой криолитозоны и в современных ландшафтно-климатических условиях не образуются. Озеровидные расширения степной зоны образовались в позднем плейстоцене в условиях существования многолетней мерзлоты в результате протаивания ледяных тел в узлах решетки полигонально-жильных льдов при освоении водотоками межблочий полигонального рельефа.

Ключевые слова: четковидные русла, озеровидные расширения русла, палеокриогенный микрорельеф, полигонально-жильные льды, малые реки

\title{
PECULIARITIES OF DISTRIBUTION, MORPHOLOGICAL STRUCTURE AND MECHANISMS OF FORMATION OF BEAD-SHAPED CHANNEL OF SMALL RIVERS OF THE STEPPE ZONE OF THE ORENBURG REGION
}

\author{
Ryabukha A.G., Polyakov D.G. \\ Institute of Steppe of the Ural Branch of the Russian Academy of Sciences - Subdivision of the Orenburg \\ Federal Research Center of the Ural Branch of the Russian Academy of Sciences, Orenburg, \\ e-mail: annaryabukha@yandex.ru
}

Local sections of riverbeds of small rivers often have a distinct structure, consisting of deep lake-shaped extensions rhythmically alternating along the length and narrow channels connecting them. Bead-shaped channels are found in all natural zones, but are most typical for the permafrost distribution zone. Analysis of satellite images and field studies have shown their wide distribution in the steppe zone. The paper discusses the distribution features, morphological structure and mechanisms of the formation of distinct channel forms of small rivers of the steppe zone of the Orenburg region. As a result of the work, a map of the distribution of clear channel forms in the region was compiled. It is revealed that they are common in the valleys of small rivers in the river basins. Ural (Kindel, Kindelka, Irtek, Healing, Great Gerbil, Lesser Gerbil, Great Kumak, Lesser Hobda, Karabutak, Or, Guberlya), p. Samara (Small Kinel, Buzuluk, Enkla, Birthday boy, Moving away, Kuwai, Swan, Magpie, Shirt), p. Sakmara (Net, Salmysh, Yangiz, Yalonga, Chebenka, Buruncha) and many others. It was revealed that regardless of the areas of their distribution on the territory of the river region with a bead-shaped channel, a number of common patterns unites. Confinement to areas of flattening of the longitudinal profile of the river valley. Typically, these are waterways of 1-3 orders with very small (less than $0.2 \%$ ) slopes and a low power flow. They flow through territories composed of loose rocks (loesses, loams, sandy loams). They have narrow valleys, with incised or adapted rectilinear channels, which often form knee-like bends. A hypothesis has been put forward that the Bead-shaped channels of small rivers, outside the permafrost zone, are relict forms, a legacy of the Pleistocene permafrost zone and do not form in modern landscape and climatic conditions. Lake-like expansion of the steppe zone was formed in the Late Pleistocene under the conditions of permafrost, as a result of thawing of ice bodies in the nodes of the lattice of polygonal-vein ice, when watercourses develop interblocks of the polygonal relief.

Keywords: Bead-shaped channel, lake-shaped channel extensions, paleocryogenic microrelief, polygonal-vein ice, small rivers

Локальные участки русел малых рек Оренбургской области часто имеют четковидное строение. Такие участки состо- ят из ритмично чередующихся по длине глубоких озеровидных расширений и соединяющих узких проток, напоминающих 
четки или бусы (рис. 1). Четковидные русла встречаются во всех природных зонах, однако наиболее типичны для зоны распространения многолетней мерзлоты. Здесь они образуются при вытаивании льда в узлах решетки полигонально-жильных льдов, в результате в русле формируются глубокие и широкие термокарстовые котловины $[1 ; 2]$. Соединяющие их водоемы обычно состоят из коротких прямых участков, сходящихся под углом, а расстояние между водоемами определяется размерами мерзлотных полигонов, по которым протекает река [3]. Генезис образования четковидных русел в степной зоне недостаточно изучен и остается дискуссионным.

Цель исследования: выявление особенностей распространения, морфологического строения и механизмов формирования четковидных русловых форм малых рек Оренбургской области.

\section{Материалы и методы исследования}

Район исследования охватывает юговосточную окраину Русской равнины, южную оконечность Уральских гор и южное Зауралье. Преобладает увалистый эрозионный рельеф, который прерывается массивами мелкосопочников, низкогорными грядами и равнинными трассами крупных рек.
Характерным является плащеобразное залегание толщи лессовых пород мощностью на Общем и Зауральском сыртах до 45 м [4].

Климат Оренбургской области континентальный $\left(\mathrm{T}_{\text {ср.год }} \sim 4^{\circ} \mathrm{C}\right)$ с холодной малоснежной зимой.го (ср. $\left.\mathrm{T}_{\text {янв }}-15^{\circ} \mathrm{C}\right)$, жарким летом (ср. $\left.\mathrm{T}_{\text {июля }}+21^{\circ} \mathrm{C}\right)$ и значительным преобладанием испарения (800-900 мм) над осадками (260-390 мм); гидротермический коэффициент составляет менее 0,6. Примерно 60-70\% годового количества осадков выпадает в период с мая по август. Максимум осадков отмечается в июле, минимум в феврале. Продолжительность безморозного периода составляет около 140 дней. Глубина зимнего промерзания составляет 120-140 см (на февраль), высота снежного покрова около 30 см [5].

Оренбургская область обладает густой и разветвленной речной сетью, которая в основном относится к бассейну р. Урал, куда входят ее крупные притоки - реки Илек, Сакмара, Урта-Буртя, Орь, Суундук, Большой Кумак. Бассейны Самары (на северо-западе) и Тобола (на востоке) представлены верховьями этих водотоков. Речная сеть области представлена 3492 реками общей протяженностью 31584 км² $^{2}$ большая часть которых относится к малым рекам и ручьям [6].

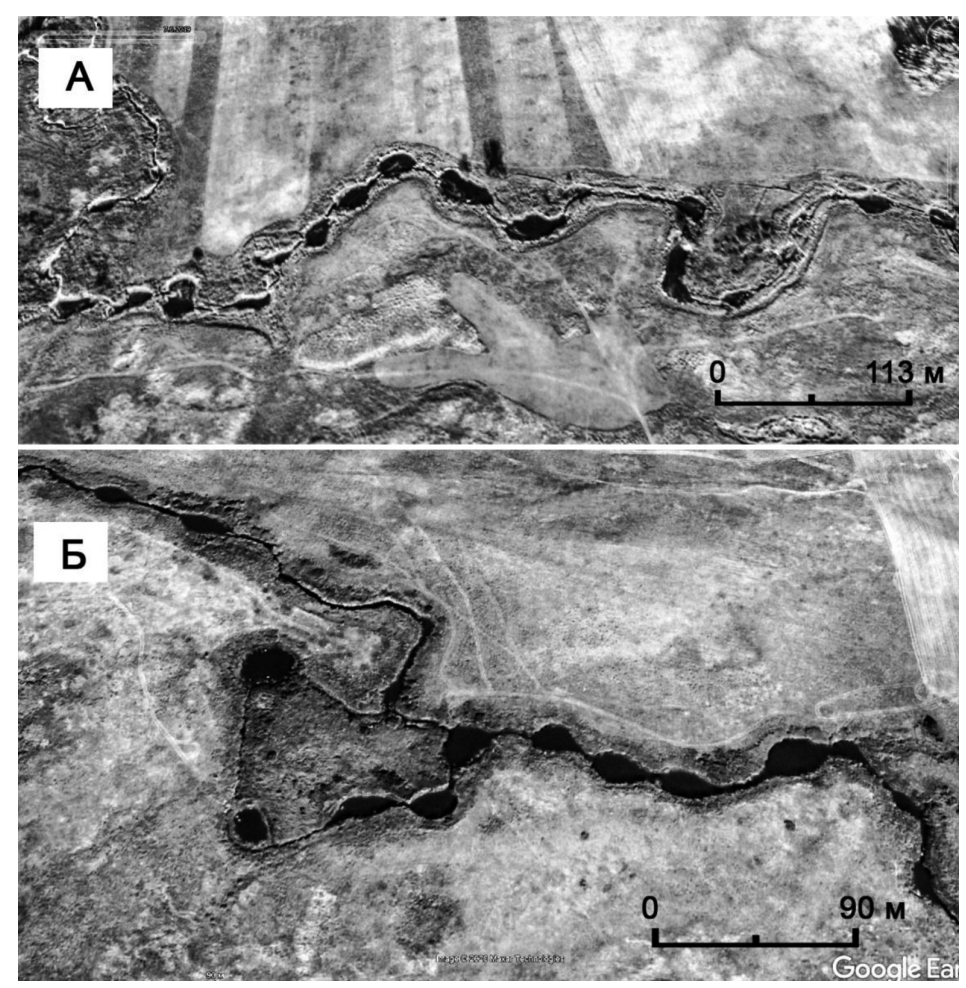

Рис. 1. Космические снимки четковидных русел в долине реки Неть: A) 52 49'47.66"C, $54^{\circ} 45^{\prime} 40.23^{\prime \prime} B$; Б) $52^{\circ} 49^{\prime} 55.96^{\prime \prime} C, 54^{\circ} 44^{\prime} 7.41^{\prime \prime B}$ (GoogleEarth) 


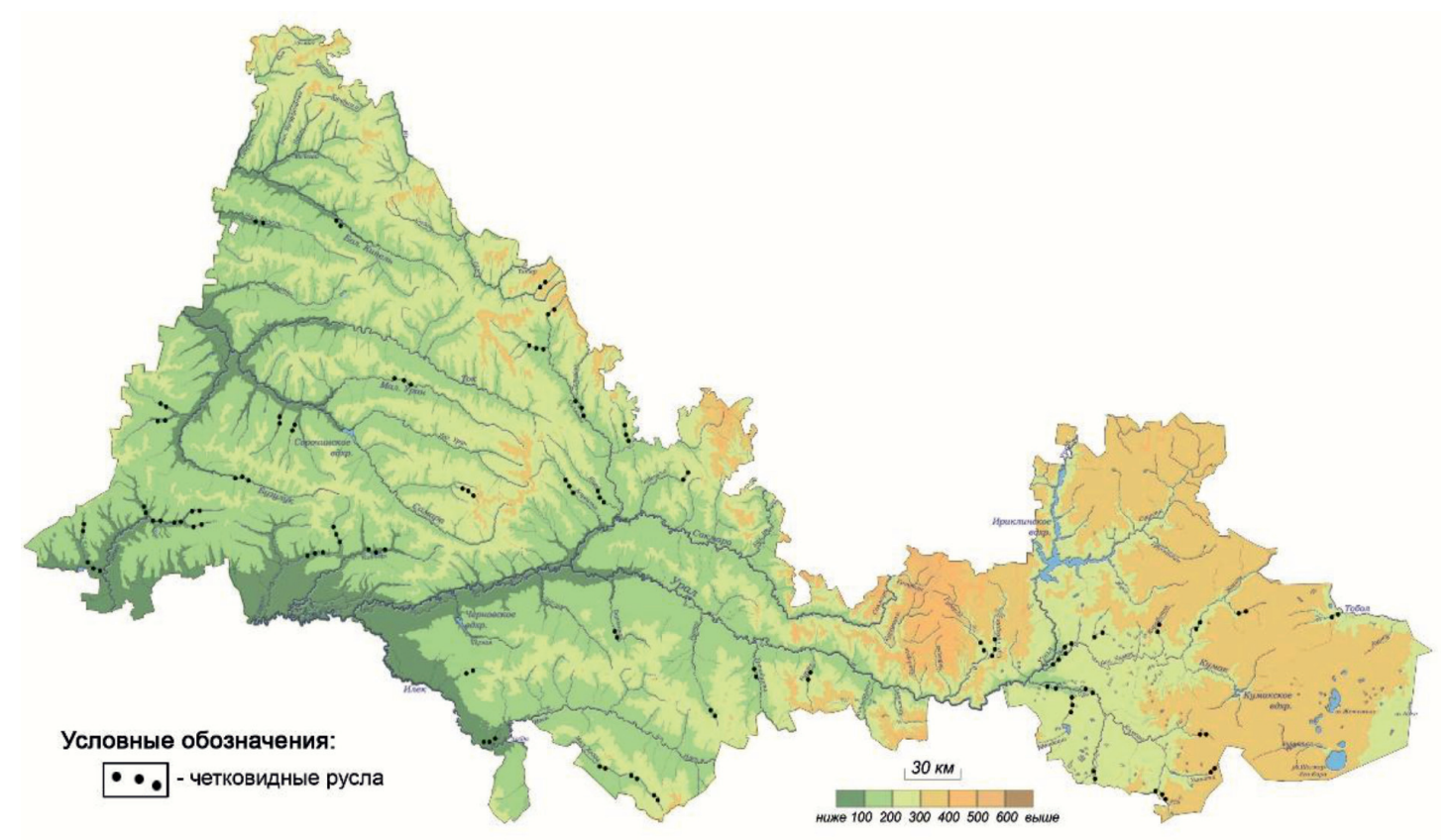

Рис. 2. Распространение четковидных русел на территории Оренбургской области

Реки относятся к типу равнинно-степных, в основном снегового и дождевого питания, с интенсивным весенним половодьем, небольшими паводками после сильных дождей летом и устойчивым меженным ординаром в остальное время. Большая часть малых рек летом пересыхает, и вода остается в виде отдельных небольших водоемов на наиболее глубоких местах (плесах) [7].

Зональный почвенный покров представлен черноземами, встречаются солонцы и солонцеватые почвы, характерна комплексность почвенного и растительного покрова. В ботанико-географическом отношении изучаемая территория относится к зоне настоящих дерновинно-злаковых степей, которые в настоящее время практически полностью распаханы. Лесная растительность обильна по поймам рек, сыртам и балкам [5].

Основными методами исследования являлись наземные маршрутные наблюдения и анализ космических снимков высокого разрешения ресурсов Google Earth, Bing Maps, Yandex Maps. Также были проанализированы многочисленные литературные, картографические и фондовые материалы, представляющие интерес в связи с решением поставленной проблемы.

\section{Результаты исследования и их обсуждение}

Морфология четковидных русел очень физиономична, они легко дешифрируются как на космических снимках, так и на местности. Выявление участков русел с озеровидными расширениями было проведено на основе анализа космических снимков. В результате проведенной работы была составлена карта распространения четковидных русловых форм на территории Оренбургской области (рис. 2).

Анализ карты показывает, что четковидные русла широко распространены на территории Оренбургской области и обнаружены на многих участках выположенных днищ долин малых рек в бассейнах р. Урал (Кинделя, Кинделька, Иртек, Заживная, Большая Песчанка, Малая Песчанка, Большой Кумак, Малая Хобда, Карабутак, Орь, Губерля), p. Самары (Малый Кинель, Бузулук, Енкла, Именинник, Съезжая, Кувай, Лебяжка, Сорока, Сорочка), р. Сакмары (Неть, Салмыш, Янгиз, Ялонга, Чебенька, Бурунча) и многих других. Четковидные формы русел также многочисленны в пойменных протоках и старицах больших рек на широкопойменных участках, особенно многочисленны они в долине р. Илек. Вне зависимости от районов их распространения на территории области реки с четковидными руслами объединяет ряд общих закономерностей. Прежде всего, они приурочены к участкам выполаживания продольного профиля речной долины - расширениям днищ долин и приустьевым областям рек, где затруднен поверхностный сток воды. Обычно это реки 
с малой мощностью водного потока, водотоки 1-3 порядка с очень небольшими (менее $0,2 \%$ ) уклонами [8]. Четковидные русловые формы получили развитие на участках слабонаклонных денудационных равнин, перекрытых плащеобразно залегающими мощными лессовыми толщами, или плоских низменных аккумулятивных аллювиальных и озерно-аллювиальных равнин четвертичного возраста, перекрытых полигенетическими суглинками и супесями, т.е. протекают по территориям, сложенным рыхлыми породами (лессами, суглинками, супесями) [4]. Реки с четковидными руслами имеют узкие долины с врезанными или адаптированными прямолинейными руслами, которые часто образуют коленообразные изгибы.

Анализ космических снимков и полевые исследования показали, что на территории района исследования четковидные русла состоят из озеровидных расширений округлой, овальной, каплевидной, серповидной или слегка продолговатой формы шириной 10-40 м (средняя ширина 25 м). Глубина, согласно данным Тарбеевой А.М. с соавторами, от 2 до 5 м [8]. Расположены они группами из нескольких близких по размерам форм. Озеровидные расширения соединены между собой узкими мелководными участками длиной от 10 до 70 м (средняя длина 35 м), шириной 1-3 м. Самый протяженный участок долины реки с четковидным формами имеет река Кинделька, правый приток p. Кинделя (бассейн р. Илек). На протяжении 20 км от устья реки вверх по течению русло осложнено чередованием озеровидных расширений (около 150) и зауженных участков длиной от 100 до 15 м.

Вне зоны многолетней мерзлоты формирование четковидных русел чаще всего объясняют неодинаковой устойчивостью горных пород и отложений к размыву или заилением малых рек, при котором на перекатах возникают благоприятные условия для их зарастания, и русло превращается в цепочку озер, образованных на месте бывших плёсов [9; 10]. Однако исследования русел малых рек в бассейне р. Урал в районе г. Орска, проведенные группой ученых МГУ, привели к выводу о том, что озеровидные расширения не являются остатками бывших плесов. Приводятся следующие обоснования. Во-первых, глубокие озеровидные водоемы не могли сохраниться при интенсивном заилении русел. Вовторых, этому противоречит частое и неравномерное расположение озеровидных расширений вдоль русла, иногда в 2-5 раз превышающее нормальную частоту расположения плесов и соответствующее примерно 5-7 ширинам русла. В-третьих, озеровидные расширения русел наблюдаются не только в пределах заиленных участков русел, но и в бывших рукавах реки Ори, отмирание которых произошло в результате врезания реки [8]. Участки долин малых рек области с четковидными руслами сложены однородными породами (обычно лессовыми суглинками), поэтому объяснить их образование неодинаковой устойчивостью горных пород и отложений к размыву также не представляется возможным [4].

Существует гипотеза о вероятности образования озеровидных расширений в руслах малых рек в результате суффозионных и карстово-суффозионных процессов. Однако, на наш взгляд, карстово-суффозионной гипотезе противоречит, во-первых, отсутствие на территории участков развития четковидных русел карстующихся пород. Во-вторых, необходимыми условиями протекания суффозионных процессов являются их приуроченности к зонам автоморфного режима и хорошего дренажа, что неприемлемо к речным долинам. Представления о суффозионном и суффозионно-карстовом генезисе западин не согласуются также с наличием регулярной последовательности расположения однотипных озеровидных расширений.

На наш взгляд, четковидные русла малых рек вне зоны существования многолетней мерзлоты являются реликтовыми формами, наследием плейстоценовой криолитозоны и в современных ландшафтно-климатических условиях не образуются. Их формирование происходило в неоплейстоцене в условиях многолетней мерзлоты с мощными полигонально-жильными льдами, когда территория области входила в перигляциальную гиперзону тундро-степей, занимавшую большую часть Евразии [11]. Существование многолетней мерзлоты в плейстоцене и, возможно, начале голоцена на территории Оренбургской области подтверждается нахождением многочисленных и разнообразных криогенных реликтов, представленных широким комплексом остаточных мерзлотно-геологических явлений: псевдоморфозами по ледяным и ледово-грунтовым жилам, инволюциями, криотурбациями, криогенными текстурами отложений, а также реликтовым палеомерзлотным микрорельефом, повсеместно закартированным на территории Оренбургской области, который определяется на космических снимках по пятнистому или многоугольному рисунку и хорошо 
дешифрируется по сети полигонов [12; 13$]$. На территории региона выделен полигонально-блочный, блочный и блочно-западинный, бугристо-западинный, продольно-полосный (веерная бороздчатость на склонах), слитно-полигональный, редуцированный и западинный палеомерзлотный рельеф [14]. Анализ космических снимков показал наличие реликтового полигонально-блочного и блочно-западинного рельефа в исследуемых бассейнах рек с размером решетки около 40 метров, что соответствует среднему значению размера суженных частей долины, расположенных между озеровидными расширениями. В пользу палеомерзлотной гипотезы говорит также морфологическое сходство четковидных русел в степной зоне и зоне многолетней мерзлоты.

\section{Заключение}

Четковидные русловые формы широко распространены на территории Оренбургской области и приурочены к выположенным днищам долин малых рек, сложенных рыхлыми породами. По мнению авторов статьи, они являются реликтовыми образованиями и в современных ландшафтноклиматических условиях не образуются. Озеровидные расширения образовались в позднем плейстоцене в условиях существования многолетней мерзлоты в результате протаивания ледяных тел в узлах решетки полигонально-жильных льдов при освоении водотоками межблочий полигонального рельефа. Таким образом, четковидные русла можно выделить как еще один тип реликтового мерзлотно-термокарстового рельефа, открытого и изученного Величко А.А. в 60-х годах XX века.

Работа выполнена по теме НИР ИС УрО РАН № № ГР АААA-A17-117012610022-5 и гранту РФФИ № 20-05-00556.

\section{Список литературы / References}

1. Губарьков А.А., Лейбман М.О. Четкообразные русловые формы в долинах малых рек на Центральном Ямале результат парагенезиса криогенных и гидрологических процессов // Криосфера Земли. 2010. Т. 14. № 1. С. 41-49.

Gubar'kov A.A., Leibman M.O. Bead-shaped channel forms as evidence of paragenesis of cryogenic and hydrologica processes in the small-river valleys of Central Yamal // Kriosfera Zemli. 2010. V. 14. № 1. P. 41-49 (in Russian).

2. Тарбеева А.М., Сурков В.В. Четковидные русла малых рек зоны многолетней мерзлоты // География и природные ресурсы. 2013. № 3. C. 27-32.

Tarbeeva A.M., Surkov V.V. Beaded channels of small rivers in permafrost zones. Geography and Natural Resources. 2013. T. 34. № 3. P. 216-220. DOI: 10.1134/S1875372813030049.

3. Уошборн А.Л. Мир холода. Геокриологические исследования. М.: Прогресс, 1988. 384 с.

Washborn A.L. The World of Cold. Geocryological studies M.: Progress, 1988. 384 p. (in Russian).

4. Карта четвертичных образований масштаба 1:2500000 территории Российской Федерации. Пояснительная записка.
СПб.: Минприроды России, Роснедра, «ВСЕГЕИ», «ВНИИОкеангеология», 2010. $220 \mathrm{c.}$

Map of Quaternary formations on a scale of 1: 2500000 of the territory of the Russian Federation.Explanatory note. SPb.: Minprirody" Rossii, Rosnedra, «VSEGEI», «VNIIOkeangeologiya», 2010. 220 p. (in Russian).

5. Соколов А.А., Чибилёв А.А., Руднева О.С., Барбазюк Е.В., Дубровская С.А., Кин Н.О., Климентьев А.И., Левыкин С.В., Павлейчик В.М., Падалко Ю.А., Петрищев В.П., Поляков Д.Г., Рябуха А.Г., Сивохип Ж.Т., Чибилёв А.А. (мл.). Географический атлас Оренбургской области. Оренбург: Институт степи УрОРАН, РГО, 2020. $160 \mathrm{c.}$

Sokolov A.A., Chibilev A.A., Rudneva O.S., Barbazyuk E.V., Dubrovskaya S.A., Keen N.O, Klimentyev A.I., Levykin S.V., Pavleichik V.M., Padalko Yu.A., Petrishchev V.P., Polyakov D.G., Ryabukha A.G., Sivokhip J.T., Chibilev A.A. (ml.). Geographical atlas of the Orenburg region. Orenburg: Institut stepi UrORAN, RGO, 2020. 160 p. (in Russian).

6. Государственный доклад о состоянии и об охране окружающей среды Оренбургской области в 2018 году. Оренбург, 2019. 222 с.

State report on the state and environmental protection of the Orenburg region in 2018. Orenburg, 2019. 222 p. (in Russian).

7. Ресурсы поверхностных вод СССР. Т. 12. Нижнее Поволжье и Западный Казахстан. Вып. 2. Урало-Эмбинский район. Л.: Гидрометеоиздат, 1970. 512 с.

Resources of surface waters of the USSR. T. 12. Lower Volga and Western Kazakhstan. Vol. 2. Ural-Emba district. L.: Gidrometeoizdat, 1970. 512 p. (in Russian).

8. Тарбеева А.М., Крыленко И.В., Сурков В.В. Озеровидные расширения русел рек степной зоны и возможные причины их формирования (бассейн р. Урал в районе г. Орска) // Геоморфология. 2016. № 1. С. 73-81. DOI: $10.15356 / 0435-4281-2016-1-73-81$.

Tarbeeva A.M., Krylenko I.V., Surkov V.V. Lake-shaped expansion of riverbeds of the steppe zone and possible causes of their formation (basin of the Ural River in the region of Orsk) // Geomorfologiya. 2016. № 1. P. 73-81 (in Russian).

9. Маккавеев Н.И., Чалов Р.С. Русловые процессы. М.: Изд. МГУ, 1986. 264 с.

Makkaveev N.I., Chalov R.S. Channel processes. M.: Izd. MGU, 1986. 264 p. (in Russian).

10. Чернов А.В. Современное развитие малых рек центральных районов Европейской части СССР // Малые реки Центра Русской равнины, их использование и охрана. М.: МО ГО СССР, 1988. С. 17-25.

Chernov A.V. The modern development of small rivers in the central regions of the European part of the USSR // Small rivers of the Center of the Russian Plain, their use and protection. M.: MO GO SSSR, 1988. P. 17-25 (in Russian).

11. Величко A.А. Эволюционная география: проблемы и решения. М.: ГЕОС, 2012. $564 \mathrm{c}$.

Velichko A.A. Evolutionary geography: problems and solutions. M.: GEOS, 2012.564 p. (in Russian).

12. Ryabukha A.G. Late pleistocene periglacial formations in landscapes of Zavolzhye-Urals region. IOP Conference Series: Earth and Environmental Science. 2018. Vol. 201. Issue 1. DOI: 10.1088/1755-1315/201/1/012018.

13. Ковда И.В., Рябуха А.Г., Поляков Д.Г., Левыкин С.В., Петрищев В.П., Яковлев И.Г., Норейка С.Ю., Ряхов Р.В. Криогенные признаки в почвах меловых полигонов Оренбургской области // Почвы в биосфере: материалы всероссийской научной конференции с международным участием, посвященной 50-летию Института почвоведения и агрохимии СОРАН. Томск, 2018. С. 37-41.

Kovda I.V., Ryabukha A.G., Polyakov D.G., Levykin S.V., Petrishchev V.P., Yakovlev I.G., NoreikaS.Yu., Ryakhov R.V. Cryogenic features in the soils of Cretaceous polygons in the Orenburg region // Soils in the biosphere: materials of an all-Russian scientific conference with international participation dedicated to the 50th anniversary of the Institute of Soil Science and Agrochemistry of the SB RAS. Tomsk, 2018. P. 37-41 (in Russian).

14. Рябуха А.Г. Реликтовая криогенная морфоскульптура Заволжско-Уральского региона // Пути эволюционной географии: материалы Всероссийской научной конференции, посвященной памяти профессора А.А. Величко. М.: Институт географии РАН, 2016. C. 277-282.

Ryabukha A.G. Relict cryogenic morphosculpture of the Trans-Volga-Ural region // Ways of evolutionary geography: materials of the All-Russian scientific conference dedicated to the memory of Professor A.A. Velichko. M.: Institut Geographii RAH, 2016. P. 277-282 (in Russian). 